\title{
Intelligent Irrigation System
}

\section{Swati Deshpande PDA College of Engineering}

\author{
Vinaya Kavalgi \\ PDA College of \\ Engineering
}

\author{
Sunita Biradar \\ PDA College of \\ Engineering
}

\author{
Suvarna Nandyal, \\ $\mathrm{PhD}$ \\ Prof \& H.O.D Dept of \\ Computer Science \\ PDA College of \\ Engineering, Gulbarga
}

\begin{abstract}
Irrigation in India to maximum extent is dependent on the monsoons, which are not a reliable source of water. Depending on the soil type, plants are to be provided with water, which is called as intelligent irrigation system. Nowadays water scarcity is a big concern for farming. Irrigation status is updated to the server or local host using Personal Computer. Arduino platform is used here for getting information via serial communication from microcontroller and to update in the server. In addition for better cropping system, fertilizers required for the crops, best crops to cultivate for the particular climatic and soil conditions are updated to server at regular basis by monitoring soil PH level, Temperature level of the field area etc., By using PC host, crop is continuously monitored.
\end{abstract}

\section{General Terms}

This project helps the farmers to irrigate the farmland in an efficient manner with automated irrigation system based on soil moisture. Soil Moisture sensor is used to find the soil moisture and based on this microcontroller drives the solenoid valve.

\section{Keywords}

Arduino Uno board, Liquid crystal display, Soil moisture sensor, Relay, Solenoid valve, PCB board, 5V power supply, $12 \mathrm{~V}$ power supply, GSM module.

\section{INTRODUCTION}

Intelligent irrigation system is a concept of automated irrigation with the use of IOT(Internet of Things). Generally most of the irrigation systems are manually operated one. These traditional techniques are being is replaced with semiautomated and automated techniques suggested an automated concept of irrigation to use the water efficiently and effectively Automated Irrigation system is implemented either based on the soil moisture or based on the user input via SMS commanding systems. Former method is an isolated irrigation system where the farmer doesn't updated with the irrigation status and later lags in smart utilization of water due to user command without considering the condition of soil. From that ever growing requirement of the population, modern techniques are introduced to control the system. To give proper attention to the land located far away from the human settlement, supervisory automatic control systems like multiterminal control systems are used since in many processes, factors like soil, salinity, irrigation, temperature, light intensity, etc. needs repeated tasks and have to work in abnormal environmental conditions of the soil and to overcome the flaws in the existing system here we are irrigating the land based on the soil humidity and at the same time the status of the irrigation is updated wirelessly to Server via serial Communication. With this farmers are intimated about fertilizers required for the crops for better yield at various conditions by measuring soil nature and the better crop cultivation based on the climatic conditions. That leads to flexibility in monitoring the irrigation system at anywhere provided with internet. The server side data can be retrieve via the internet to access it for easy to handle the devices and now a day's internet is also necessity for all human beings then only it will become a booming to continuous monitoring and controlling of irrigation system.

\section{PROBLEM STATEMENT}

1. Irrigation scheduling

2. Over watering

3. Under watering

1. Irrigation scheduling

Is the biggest problem in the current irrigation methods: Irrigation scheduling is the process used by irrigation system managers to determine the correct frequency and duration of watering. The following factors may be taken into consideration: Precipitation rate of the irrigation equipment - how quickly the water is applied, often expressed in inches or mm per hour.

\section{Questions Arising}

- When do I water?

- How long do I water?

\section{Overwatering}

Over watering is one of the more common causes of plant problem. Heavy and poorly drained soils are susceptible to becoming waterlogged. Roots growing in waterlogged soil may die because they cannot absorb the oxygen needed to function normally. The longer the air is cut off, the greater the root damage. The dying roots decay and cannot supply the plants with nutrients and water. Damage caused by over watering is frequently misdiagnosed as pest damage. However, pest damage rarely causes roots to concentrate near the surface of the soil. Plants stressed or injured by water logging can become abnormally susceptible to certain fungal pathogens. Phytophthora spp. for example, cause root rot most often in soils that are periodically waterlog.

\section{Under watering:}

Under watered plants typically grow slowly and have brown, dry leaf edges. The plants may drop leaves or flowers, or the plant may fail to flower entirely. The lower leaves usually suffer first, becoming yellowed and curled. Eventually the plant dries up and dies. Check soil moisture at least once weekly. Water when the top 1 to 2 inches of soil begins to feel dry, but before it dries out completely. Outdoor plants usually require more frequent watering than those kept indoors. Check the soil moisture 
of outdoor potted plants daily and garden plants at least twice as a week.

\section{LITERATURE SURVEY}

[1]HarithaTummala , SwathiNallapati ,Asst.professor in DhanekulaINTELLIGENT IRRIGATION CONTROL SYSTEM Institute of Engineering \& Technology in Dept of E.C.E, A.P, India 2Asst.Professor at VignanNirula Institute of Technology and Science for Women, A.P, India

SSRG International Journal of Electronics and Communication Engineering (SSRG-IJECE) - volume1 issue10 Dec 2014

Fast growing technology of wireless sensor networks (WSN) is an advantage to the agriculture sector. Modern advances in the development of WSN offer new trends like Precision Agriculture (PA). In the proposed system the irrigation controller normalizes the desired moisture level in the agricultural soil by controlling the water flow of the irrigation pump based on the sensor readings, by switching the pump between $\mathrm{ON}$ and OFF states.

[2]INTELLIGENT IRRIGATION SYSTEM N. Dinesh kumar1, S. Pramod2 \&chsravani3 Associate Professor \& HOD - EIE, Vignan Institute of Technology \& Science, Deshmukhi, Andhra Pradesh, India, UG Students, Department of EIE, Vignan Institute of Technology \& Science, Deshmukhi, Andhra Pradesh, India Application Developer, IBM India Pvt. Ltd., Bangalore, Karnataka, India

International Journal of Agricultural Science and Research (IJASR) ISSN 2250-0057 Vol. 3 Issue 3, Aug 2013, 23-30 @) TJPRC Pvt. Ltd.

Irrigation in India to maximum extent is dependent on the monsoons, which are not a reliable source of water. Depending on the soil type, plants are to be provided with water, which is called as intelligent irrigation system. This paper discusses the prototype design of microcontroller based Intelligent irrigation system which will allow irrigation to take place in zones where watering is required, while bypassing zones where adequate soil moisture is indicated. Other feature of this prototype is pesticide sprinkling system where the mixture is prepared in required proportion deserved by the plants automatically (required ratio is preloaded), there-by preventing the human mistakes to maximum extent. At present costsaving technology, labor-saving are the addressing key issues inirrigation.

[3]REVIEW PAPER BASED ON AUTOMATIC IRRIGATION SYSTEM BASED ON RF MODULE Ms. DeweshvreeRane PG Scholar - VLSI, Sevagram, Wardha, India Prof. P. R. Indurkar Professor, BDCE, Sevagram, Sevagram, Wardha, India Prof. D. M. Khatri Assistant Professor, BDCE, Sevagram, Sevagram, Wardha, India

\section{IJAICT Volume 1, Issue 9, January 2015} Doi:01.0401/ijaict.2015.09.01 Published on 05 (02) 2015

In India, agriculture plays an important role for development in food production. In our country, agriculture are depends on the monsoons which is not sufficient source of water. So the irrigation is used in agriculture field. In Irrigation system, depending upon the soil type, water is provided to plant. In this paper, automatic irrigation system based on ARMs and RF module.

[4]INTELLIGENT DRIP IRRIGATION SYSTEM TupeAlok R. GaikwadApurva A. .KambleSonali U. Department of
Information Technology Department of Information Technology Department of Information Technology JSPM's JSCOE, Pune, India JSPM's JSCOE, Pune, India JSPM's JSCOE, Pune, India

International Journal of Innovative Research in Advanced Engineering (IJIRAE) ISSN: 2349-2163 Issue 2, Volume 2 (February 2015) www.ijirae.com

Drip irrigation is artificial technique of providing water to the roots of the plant. It is also called micro irrigation. Drip irrigation system is based on remote monitoring as well as controlling. In proposed system both mobile and computer are monitor and control the drip devices. In Intelligent Drip Irrigation system, an android mobile sends commands to computer to control drip irrigation system, here different sensors like humidity, temperature, light etc. will use for detection purpose. These sensors send the real time values to micro-controller and micro-controller send these values to computer (Cloud server) via serial communication.

\section{SYSTEM DESIGN}

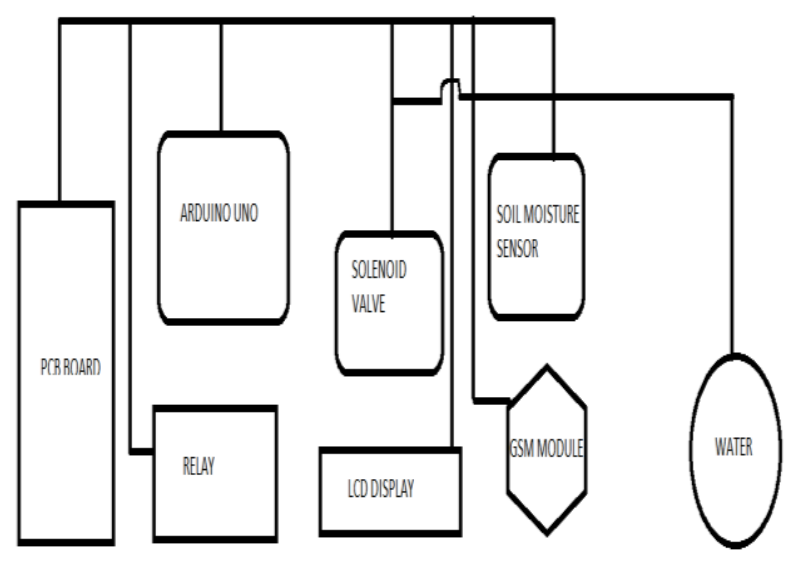

On PCB board, one horizontal line is made of $5 \mathrm{~V}$ and other vertical line is made of $12 \mathrm{~V}$ and one more is ground(GND).

Arduino board is connected to the PCB board and arduino that is used for coding.

Relay is connected which acts as switch and automatically ON $\&$ OFF the switch based on the delay.

Then solenoid valve is connected to the arduino board and PCB board to display the rate of time water supply.

The soil moisture sensor is used to know the moisture level in the soil that is connected to the PCB board and to the arduino kit.

At last the water tank is used for supplying of the water to the plants.

Arduino uno board is used for the whole progress of the project. It acts as the heart of the project and acts as the microcontroller of the project.

The branches of the ardunio board are soil moisture sensor, temperature sensor, the solenoid valve. 


\section{Decision Table}

\begin{tabular}{|c|c|c|c|c|}
\hline Crop & Soil Moisture Sensor & Condition of the Soil & Delay & Motor Status \\
\hline Maize/Rice & $0-300$ & Wet Soil & 5 Seconds & Off \\
\hline Maize/Rice & $700-1023$ & Dry Soil & 5 Seconds & On \\
\hline
\end{tabular}

Soil moisture sensor is used to measure the water content in the soil; it gives value in terms of digits with 1000 being wet and 300 being dry.

Temperature sensor is used to measure the temperature of the soil depending upon which we can decide the amount of water required by the soil. It gives values in terms of digits and unit as Celsius.

The solenoid valve has 2 outlets one for the inflow of water and the other for the outflow of the water.

The arduino program consists of 2 Parts one is the void setup () and the other is the void loop (), these two functions are the main functions of the project.

Void setup will initialize all the pins required for the board and the lcd display with pin numbers $2,3,4,5$ and 11,12 .

Void loop will run the conditions in a loop until and unless the program is stopped.

In this way, the sensors sense the soil and allow the water to flow and stop respectively and this runs in a loop till infinity.

All the information of this will be sent to a registered mobile number using the GSM module.

Farmer will get the information by getting the messages through the GSM module

\section{WORKING}

Irrigation is defined as artificial application of water to land or soil.

Irrigation process can be used for the cultivation of agriculture crops during the span of inadequate rainfall and for maintaining landscapes.

An automatic irrigation system does the operation of a system without requiring manual involvement of persons.

Every irrigation system such as drip, sprinkler and surface gets automated with the help of electronic appliances \& detectors such as computer, timers, sensors and other mechanical devices.

An automatic irrigation system does the work quite effectively and with the positive impact on the place where it is installed. Once it is installed in the agricultural field, the water distribution to crops becomes easy and doesn't require any human support to perform the operations permanently.

The automatic irrigation system on sensing soil moisture project is intended for the development of an irrigation system that switches submersible pumps ON or OFF by using relays to perform this action on sensing the moisture content of the soil. The main advantage of using this irrigation system is to reduce human interference and ensure proper irrigation.

\section{RESULTS}

The results of this project are decided upon 2 ways i.e. we can find out if the soil is dry or wet.

Once we know the condition of the soil, deciding how much amount of water is required by the plants becomes very easy.

The soil moisture sensor gives the values in terms of digits saying 1023 or 600 etc.

Here from the decision table we can see that 1023 gives the indication of full dry soil.

And 300 is the indication of complete wet soil, so depending upon that the motor is turned on and off respectively.

The whole process takes place in a loop and it becomes easy for the farmer to monitor the growth of the plants by giving them enough amount of water whenever the soil requires

Necessity of irrigation system in India is immense.

Importance of agriculture and need to meet the present demand and export of agriculture of products.

Technology to promote growth and increase the agriculture.

Enhanced automated system to replace manual irrigation system with an machine controller IOT controlled.

\section{CONCLUSION}

The overall project is to develop a Automated Intelligent Irrigation system to control automatic supply water, liquid fertilizers based on moisture and temperature inputs.

The basic model is prepared and working fine.

Coding for operating water valve is prepared and tested.

In the next phase, GSM module will be used to send information to a registered mobile.

The GSM module is connected to the arduino board and the coding is done.

Whatever the condition of the motor it will be sent as a alert message to the mobile phone.

The future scope of the project will be using different fertilizers to the plants and they can be automatically controlled as well.

Using GSM module we can send the information to a registered mobile number.

\section{ACKNOWLEDGEMENTS}

We thank all the teachers and staff members that helped us through this paper, last but not the least we would like to thank our HOD madam for guiding us in this project. 


\section{REFERENCES}

[1] HarithaTummala , SwathiNallapati ,Asst.professor in DhanekulaINTELLIGENT IRRIGATION CONTROL SYSTEM Institute of Engineering \& Technology in Dept of E.C.E, A.P, India 2Asst.Professor at VignanNirula Institute of Technology and Science for Women, A.P, India SSRG International Journal of Electronics and Communication Engineering (SSRG-IJECE) volume1 issue10 Dec 2014

[2] INTELLIGENT IRRIGATION SYSTEM N. Dinesh kumar1, S. Pramod2 \&chsravani3 Associate Professor \& HOD - EIE, Vignan Institute of Technology \& Science, Deshmukhi, Andhra Pradesh, India, UG Students, Department of EIE, Vignan Institute of Technology \& Science, Deshmukhi, Andhra Pradesh, India Application Developer, IBM India Pvt. Ltd., Bangalore, Karnataka, India International Journal of Agricultural Science and Research (IJASR) ISSN 2250-0057 Vol. 3 Issue 3, Aug 2013, 23-30 @ TJPRC Pvt. Ltd.
[3] REVIEW PAPER BASED ON AUTOMATIC IRRIGATION SYSTEM BASED ON RF MODULE Ms. DeweshvreeRane PG Scholar - VLSI, Sevagram, Wardha, India Prof. P. R. Indurkar Professor, BDCE, Sevagram, Sevagram, Wardha, India Prof. D. M. Khatri Assistant Professor, BDCE, Sevagram, Sevagram, Wardha, India IJAICT Volume 1, Issue 9, January 2015 Doi:01.0401/ijaict.2015.09.01 Published on 05 (02) 2015.

[4] INTELLIGENT DRIP IRRIGATION SYSTEM TupeAlok R. GaikwadApurva A. .KambleSonali U. Department of Information Technology Department of Information Technology Department of Information Technology JSPM's JSCOE, Pune, India JSPM's JSCOE, Pune, India JSPM's JSCOE, Pune, India International Journal of Innovative Research in Advanced Engineering (IJIRAE) ISSN: 2349-2163 Issue 2, Volume 2 (February 2015) www.ijirae.com 